Research Article

\title{
Motivation, a Key Variable within Brand Management
}

\author{
Valentina Iuliana Diaconu \\ University of Economic Studies, Bucharest, Romania \\ valentina.iuliana.diaconu@gmail.com
}

Received date: 15 March 2017; Accepted date: 8 June 2017; Published date: 5 July 2017

Academic Editor: Gârdan Iuliana Petronela

Copyright (C) 2017. Valentina Iuliana Diaconu. Distributed under Creative Commons CC-BY 4.0

\section{Introduction}

Economical development buying behaviour has become harder to measure. Brand managers have to create marketing strategies adapted to each market segment so that their brands become more competitive, earning market shares and notoriety. Understanding consumer motivation is undoubtedly essential when increasing loyalty through advertising or growing a brand's personality or improving a brand's reliations with consumers. There are a large number of questions to which motivation can offer answers. Why isn't motivation stable? Why do people so often change consumption behavior? What are the decisions that a marketer must make when there is a need for increasing market share for a brand? What resides in the consumer's "black box" and how can the motivational centers be triggered? All these questions are in fact parts of the process through which brand management tries to attract more consumers. The purpose of this paper is to create a series of associations and causality relationships between consumer motivation for purchasing high-end clothing items and brand management. The analysis of purchase motivations was based on a qualitative study in the form of 32 in-depth interviews with luxury products users. The respondents were selected from a certain social category, being entrepreneurs or specialists working in the fashion industry or in fashionrelated industries.

Keywords: consumer motivation, luxury fashion, brand management, personality

\section{Consumer Motivation through the Perspective of Brand Management}

Motivation refers to the behavioural manifestations of an individual in the process of buying and consumption of goods or services that can be determined by the appearance of a state of tension, due to the existence of an unsatisfied need. Motives represent variables that can influence buying behavior, as a result of biological, social and physical factors (Cătoiu and Teodorescu, 2003). Motives are characterized at a multidimensional level, are delimited by the

Cite this Article as: Valentina Iuliana Diaconu (2017), "Motivation, a Key Variable within Brand Management ", Journal of Marketing Research and Case Studies, Vol. 2017 (2017), Article ID 505739, DOI: 10.5171/2017. 505739 
biological and social, by states of internal tension and knowledge. Buying or nonbuying motivation is influenced by the individual's needs: the need for safety, food, self-improvement, understanding or empathizing, the need to explore and learn (Maslow, 1943). The consumers' purchase decision starts from the acknowledgment of the need, searching for information, selecting the alternatives, the actual purchase and the continuation of using the same brand. When selecting a brand, consumers use the information that they have from previous experiences, from other sources or from the advice and recommendations given by friends or family. Beside price, characteristics, quality - the availability of the products and that of the brands that the customer wants depends on advertising, the brand's image, the brand's consciousness, word-of-mouth advertising, past experience (Kotler and Keller, 2012).

Motivation can represent the ability to make right decisions when individuals have relevant information and have high hopes for a products or service (Hoyer and MacInnis, 2010). Consumers also have social needs: social experience, the need to communicate with others, the need to belong to a group, the need to gain a certain status or position within society, the need for authority, safety, but also the need that results from the pleasure of negociating. (Foxall and Goldsmith, 1998). Motivations can be, on one side, aspects of the individuals' uniqueness, and on the other side, a social and cultural variable. The structure of motivations can also be determined by other characteristics such as the amount of positive or negative experiences of an individual that influences the buying behavior (Arnould and others, 2002). Motives can be utilitarian when individuals wish to satisfy immediate needs or hedonist, when the client regards the buying experience from a positive perspective and enjoys any activity related to shopping (Fischer and Arnold, 1990; Hirschman, 1983). The motives that are utilitarian in nature can be represented by the functional benefits that are offered by the products or services that are purchased (Overby \& Lee, 2006). The utilitarian motives that appear in the case of online shopping can include purchase intention when navigating the given website, free shipping, the possibility to return the products or discounts and coupons that are offered for purchases that surpass a certain sum of money (Noble and others, 2006).

Taking into account the hedonist motives, 5 segments of buyers have been determined: minimalists, collectors, suppliers, enthusiasts and conservatives (Arnould and Reynolds, 2003). Motivation can result from an acquisition that is based on the product's identity and significance. The purchase is concentrated on the logic followed by each individual: the influence from friends and family, social and economical pressure, advertising and unique design (Levy's, 1959). Consumers use luxury items because they are motivated by the feeling of uniqueness, by the desire to express their personality, the desire to wear a new product, cleared and defined design and fun (Guiot and Roux 2010). Starting with these aspects, brand managers must build marketing strategies that are adapted to the needs of consumers, but these needs are not so easily identified.

The challenge in brand management comes from the impossibility of knowing if a consumer needs a certain product and creating a need where none exists, eventually causing pleasure as a result of use. Motivation can make brands stronger than established competitors, because consumers prefer to use products that respect international standards of quality, morality, but also satisfy their needs (McClelland and Burnham, 2000). A strong brand needs a strong image that captures the essential, the story of a brand. Achieving a high degree of loyalty towards a brand is the main objective in the management process. Loyal consumers are very important for the company because it is much more costly to recruit new customers (Keller, 2003) and that is why motivation is key. Consumers can also be motivated to consume a certain brand if the brand's personality is humanized, or if they 
perceive the brand as a trustworthy partner in consumption. Brands are created to influence potential users through their identity, image or reputation (Balmer and Greyser, 2003).

On the other hand, the experience that the consumers have with the brand is very important. The experience can be defined by a series of feelings, emotions, behavioural models that are triggered by certain stimuli belonging to the brand. A pleasant experience with a given brand can determine consumers to buy its products and to recommend them to potential consumers. 0 positive global attitude emphasizes the fact that the created experience can have an influence on the purchase behaviour (Brakus and others, 2009). The official website of a brand can be another tool that influences consumption motivation. Brand managers must take into consideration the degree of utilisation, accessibility, credibility, design, functionality, utility and ease of access of the information that is necessary to the user (Garcia and Diaz, 2010).

\section{Conceptual Model and Hypotheses}

This paper is based on a qualitative study that was comprised of 32 interviews that were individually held with users of luxury clothing items, men and women, ages between 21 and 60 . This research took place between November 2015 and March 2016. The content analysis that was elaborated based on the in-depth interviews outlined three data units: respondents' opinions on luxury clothing items, types of motivations that influence the consumption of luxury clothing items and existing differences between respondents that took part in the qualitative research. The qualitative research has as its objective the identification of variables that influence the buying motivations of luxury clothing items. In order to study consumer behavior through a motivational perspective, a conceptual model has been established in order to analyze motivation in relation to the process of brand management.

The conceptual model must support the construction of a strong brand that bases itself on a direct and tight link between consumer behavior, brand management processes and the product brand. The marketers' responsibility is to ensure that consumers have the best possible perception in regards to the brand that is promoted. A positive relation must be constantly developed with the market segment that is addressed by the brand through short term, medium and long term strategies (Kapferer, 2004). Specialists can build links starting from tangible and intangible elements offered by the brand to consumers (Hislop, 2001). 


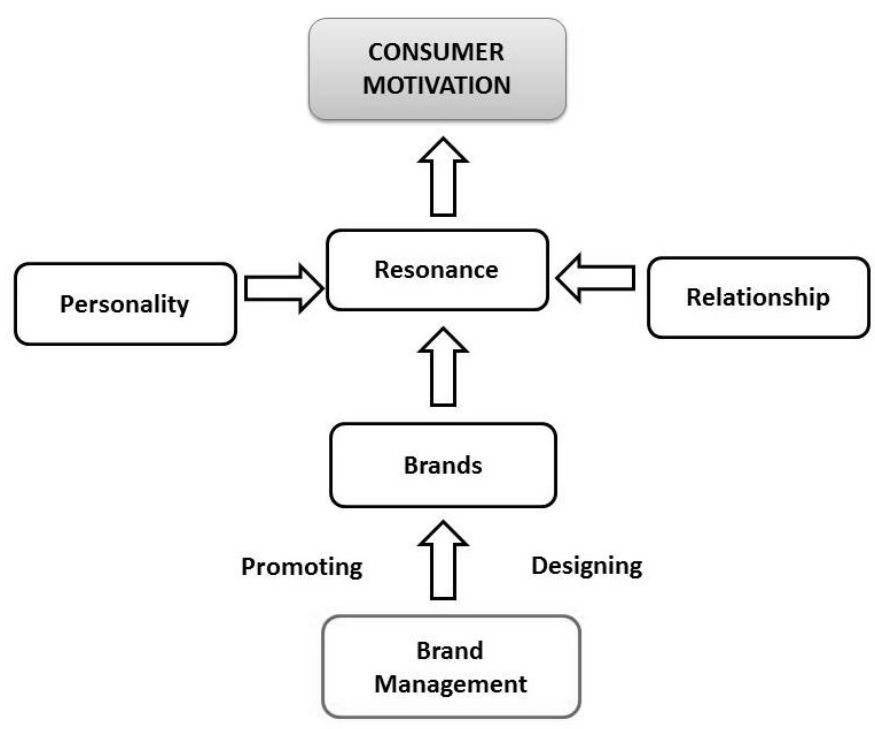

Figure 1: Conceptual model of analysis of consumer motivation from a brand management perspective

Source: Made by the author

The conceptual motivation found in figure 1 illustrates the manner in which consumer motivation influences brand management. The process starts from the primary phase of creating a brand going up to the way in which the brand resonates with consumers.

The process of creating a brand is long and takes emotional and rational implication, creativity, perseverance and consistency. The brand, aside from human force, represents the most important resource for a company that desires to prosper and develop, but in order to accomplish these, a brand needs a clear identity, a powerful name and a strong link with the company's desired business model. The brand will further represent the purpose, the culture and the company's values so that consumers recognize and recommend it. It must stand out through its design, shape and packaging or through colors. After its birth, the brand follows the process of promotion as a reflection of consumers that value a series of intrinsic or extrinsic variables. Each individual classifies a brand depending on personality or past consumption experiences and tends to attribute a "label" to the brand that is more or less subjective, with a primordial role in the image that is transmitted throughout the market.

The brand's identity has to be strong in order for people to remember it and want to buy it or return to that certain company (Keller, 2013). After this stage, the key attributes that differentiate the brand from its competitors must be identified, because this way the decisions behind the buying process can be identified along with a pattern in which brands are classified. In order to show these aspects, a communication and promotional strategy must be elaborated in accordance with the brand's identity and personality. Regarding the brand's personality, consumers tend to be closer to brands with human personalities (Keller, 2001). 
The personality of a brand has as its main building block the understanding of the company's business model and that of its purpose, the second component is illustrated by the importance of identifying and understanding the desired target market. Furthermore, an important aspect is reppresented by the competitive advantage that the created brand has as opposed to its competitors. Is it necesarry to establish the consumer's reason to purchase a product from brand $X$ and not brand Y's product. The competitive advantage helps in improving the business model and the continuous development of the brand. Along with the brand's developement, the process is not interrupted but rather the monitoring is continued. The brand must be protected and monitored in order that no competitor "borrows" defining elements from the said brand. Another important aspect for brand management is the consumer's reasoning when he or she decides to purchase or to not purchase a product or service and does not hold all the information that is necessary for the decisional process. Consumer motivation can be studied as reactions and cognitive processes (Howard \& Sheth, 1969), it bases itself on the assumption that the consumer behaves rationally during the acquisition, the process is repeatable and is the result of the stimuli originating from the external medium ( input variables). The motivation of individuals can depend on many variables: synthetic stimuli such as physical attributes, price, quality; symbolic stimuli such as verbal or advertised messages used by marketers and social stimuli, the origini of whom contains the consumtion medium, family, reference group or society.

Furthermore, the relationships between brand and consumers must not be neglected because they need to be established as bonds of trust between partners. The moment a brand has reached peak levels of resonance with the client, one can say that a profound bond has been created at a psychological level, one that can include repeated purchases, the adoration of the brand's products, the feeling of belonging to a group but also the feeling of active implication.

The relationship with a brand can affect or develop the business, that is why it is important that brand managers find the main consumption brakes within consumer motivation, in order to determine the increase in the demand for a certain brand. For example, the lowering prices can be a good short term strategy, but in the long term the brand's image can be perceived as being that of poor quality or accessible to a wide audience. A positive exchange relation between brand and consumer must be maintained by the offering of some advantages that are superior when compaired to competitor brands (Clark \& Mills, 1979). When a client purchases a good, he or she expects immediate benefits in order to recover his or her investment. Another type of bond that brands can create with consumers can be determined through innovative behavior and innovative personality of individuals that take risks when it comes to a new brand or an existent one (Foxal \& Bathe, 1991). Consumer curiosity is also another factor on which a company can build strong positive bonds, because it represents the desire for knowledge through intrinsic motives (Baumgartner \& Steenkamp, 1996). Curiosity can originate from a single stimulus that awakens the desire for consumption or from a variety of sources that are influenced by the state of boredom. Motivation based on curiosity underlines the desire for learning and development of the consumer, but also for the exploration of the external medium. Furthermore, the experience that is accumulated by the consumer in search for products and services that satisfy his or her needs has led to the creation of levers that influence purchase motivation. On the one hand, physical experience with the brand, consumption experience have determined the strength and the intensity of the brand, variables that can vary based on valence, because some experiences can be positive and others negative. On the other hand, there is the possibility that some experiences may 
form spontaneously, lasting for short amounts of time, while some that are caused deliberately can last longer. Experiences that last longer are stored within the consumer's memory and can, in the long term, influence their satisfaction regarding directly the experience with the brand and the loyalty to it (Oliver, 1997). Knowledge of a consumer brand is interconnected with the consumer's cognitive map (Peter \& Olson, 2004, Olson 1978). The consumer can recognize a brand because it is stored inside his or her consumption memory, where the sum of memories and descriptive information regarding the brand reside.

When the client resonates with a brand, he or she can be motivated easier in order to test a product or to purchase it. From the moment this link is established, strategies must be built in order to maintain a longer relation with the consumer. A brand's ability to maintain its consumers can be transposed through the offering of excelent pre-sale or post-sale services that can determine the attraction of new customers. In the luxury industry's case, the exclusive character and the power must be felt in every detail. On the other hand the relationship between brand management and consumer personality must be a positive one, supported by honesty, because once individuals have been won over, they will bring income to the company in the long term.

In this case, the qualitative research that was conducted regarding the motivation for purchasing luxury clothing items has shown a series of aspects such as: the relation between a luxury brand and consumers is complex, based on emotions, feelings and consumption experiences; trends as a reflection of a social, political, economical and artistic environment. Luxury clothing brand consumers are different from the ones that prefer brands that are widely available to all audiences, they appreciate fashion and care about their image and their social status, regardless of their degree of education or their income. For them, luxury means "a product of high quality with a price that is prohibitive for a large part of the population, that offer a special status to the consumer", "quality no matter the cost", "being associated with people of great financial power".

\section{Research Results}

The qualitative research started from the luxury clothing market that is marked by continuous growth. The global market for clothing item is currently estimated to value 3 trillion dollars, representing $2 \%$ of the world's GDP. This industry contains many segments that are addressed to women, men and children. The luxury goods market has registered a growth of $3 \%$ at a global level in 2016. The US is the country with a constant rise in luxury goods sales, being expected that it will remain the leader in this regard up to 2018, followed by China, Russia, Brazil and other emerging states. Among the opportunities for growth, digitising and ecommerce are the ones that luxury brands are using more and more frequently. Beside the classic luxury products, we can observe that new segments are starting to appear: the so-called "new luxury", notion defined by products and services with a higher level of quality, taste and aspirations than other goods from within the luxury industry. Classic or traditional luxury is no longer enough in order to reach the consumers or to create a real luxury experience. Consumers have changed their attitude toward "durable luxury", meaning that they are currently motivated by technological changes, by the environment and by economic factors that determine a consumption demand that is more conscious (Euromonitor, 2016). Furthermore, luxury fashion is heading toward the concept of feeling good in your own skin, looking young and healthy. Thus, an increase in the creation of clothing that is versatile, youthful, that allows doing sports but also attending special occasions (BOF, 2017).

The paper conveys a first point of view of the qualitative research regarding the purchase motivation of luxury clothing items. The luxury products that were analysed within 
the research were luxury clothing products, apart from accessories or leather products: shirts, dresses, suits, trousers etc. The qualitative research was conducted through 32 in-depth interviews with respondents within the social categories $\mathrm{A}, \mathrm{B}, \mathrm{C} 1$, women and men, with average or above average incomes, age between 21 and 60. The qualitative study that was conducted was an exploratory one. The respondents were selected for the in-depth interview with a selection questionnaire comprised of 13 filtering questions and multiple choice questions. Each in depth interview lasted 95 minutes. The participants of the conducted study work in fields that are related to luxury and are users or non-users of luxury clothing items. The chosen recruting method was the "snowball" method, through which the respondents recommended other people from the environments in which they work to take part in the study. The questions that were used within the interview guide had the following objectives: identifying the types of luxury clothing users and their perceptions regarding products, identifying visible motivations and less obvious motivations that determine consumers who use luxury products, but also identifying the feelings and the experience felt within the decisional process. One of the qualitative techniques that was used during the in-depth interviews was the Higgledy-piggledy technique, where respondents had to choose between multiple luxury clothing characteristics from an unsorted list of words. Another technique that was used was the Laddering technique, where respondents had to answer questions such as: "What do you think about $\mathrm{X}$ (product)? " or "What does Y (product) mean to you?".

The qualitative research's results regarding the motivation of purchasing luxury clothing items have been interpreted with a content analysis that revealed a series of aspects that are important for brand management. Thus, respondents can be luxury product users or non-users, can have a certain education and culture regarding luxury and are willing to try clothing products that satisfy their social, economical and personal needs. The majority of respondents already have a formed clothing style that they express daily or only when attending fashionable events or family events. When they choose to wear luxury clothing, they are motivated by emotions, memories that cause them pleasure, pride and a general good feeling, which means that hedonistic motivation, along with utilitarian motivation determines the consumptions of high-end products. Another projective technique that was used was photo elicitation, technique that has allowed the study through visual elements of consumer motivation of purchasing of luxury clothing items. This technique has identified a matrix of positive memories: "grandparents' old summer home", "a trip with the family", accompanied by a visible nonverbal behavior illustrated by facial expressions and gestures that depend on the state of joy or nostalgia relieved by the respondents within the individual interview. The main identified motivations that influenced the respondents into utilizing or buying luxury clothing items are represented by: the motivation for power and recognition, uniqueness, the motivation to be a trendsetter, the motivation to wear clothes of a high quality, loyalty and admiration toward a known brand, the desire to learn, freedom of expression through innovation and new combinations, refinement and elegance, power, status, timelessness, personal reward, curiosity, the desire to improve and learn. With these in mind, it can be stated that the motivation to use or to purchase luxury clothing items does not depend only on variables such as income, education or the influence of others but that it also strongly correlated with memories and personal experiences, lifestyle, perceptions, degree of implication, the desire to stand out or the desire to learn and develop. Also, when it comes to luxury, motivations are delimited by hedonism and utilitarianism. Utilitarianism is linked with durability, reliability, exagerated costs for an extraordinary quality of the products, while hedonistic motivations are responisble for joy, pleasure, general euphoria, fun and pleasant memories. 
Along the techniques that were mentioned previously, two other instruments were tested in the analysis of the tone of voice, but also the emotions that were felt by the respondents. The participants' tone of voice throughout the duration of the individual discussions was studied with a computerbased instrument, IBM Watson Developer Cloud - Tone Analyzer. Based on this instrument a series of hidden motivations were discovered, motivation that resided within the participants' nonverbal communication regarding the study at hand. The second instrument that was used was AlchemyAPI, an instrument that uses the processing of natural language, artificial intelligence, deep learning, also being capable of doing text analysis from which unstructured data can be extracted. The most mentioned motives during the discussions were: the pursuit of REFINEMENT, the display of ELEGANCE and reaching personal PRESTIGE, which means that when individuals choose to use a luxury clothing article they are influenced by a certain style, by the feeling of renown, the display of refinement respectively, that is cultivated in time through education or experiences accumulated in the decision making process.

Thanks to the IBM Watson Developer Cloud Tone Analyzer program the impact of the tone belonging to the respondents' voice could be analyzed when they were encouraged to share their perceptions and ideas regarding the consumption of luxury clothing products. For example, anger was the predominant emotion of one of the individuals as he talked about luxury fashion, but with a small to medium intensity. This emotion is acknowledged, fact that can show that this particular respondent is discontent with the social pressure of fashion that constrains through the social recognition of individual style. It may very well be that this consumer uses luxury clothing only because he is influenced by social tension. At the opposite pole, joy and happiness appear when the respondents recounted moments when they wore luxury clothing or talked about pleasant memories. On the other hand, at a closer analysis of the transcribed text that came from the participants' respondents, it can be observed that the noun fashion is a key-word, being frequently mentioned, fact that can mean a positive emotion toward this field. Thirdly, responses have been interpreted with a content analysis taking into account several criteria such as the 5 personalities of a brand (Aaker, 1997): emotion, sincerity, cognition, sophistication, inflexibility. 


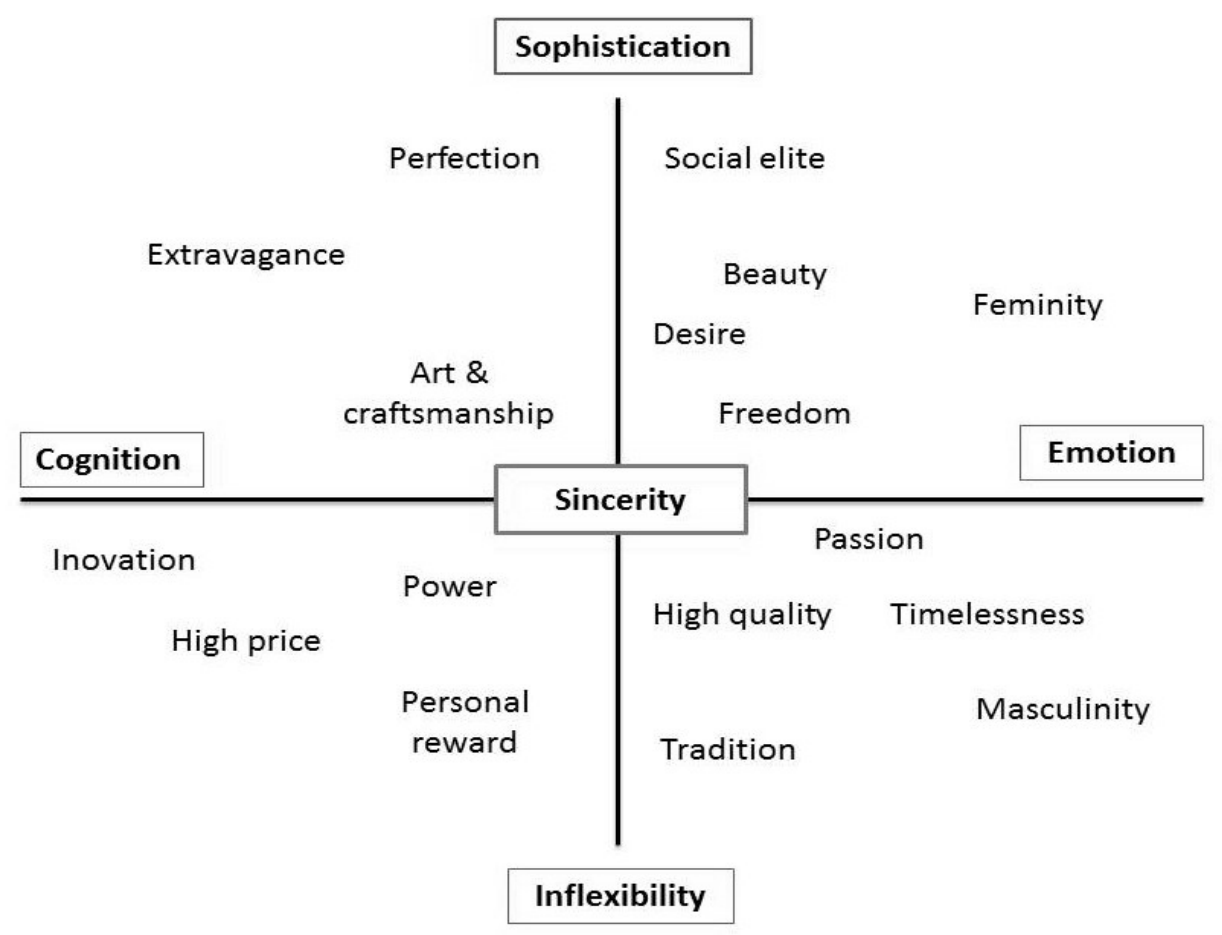

Figure 2: Personality type map

Source: Made by the author

According to the figure above, it can be deduced that the respondents of the qualitative research can be sorted according to the 5 types of brand personality. The attributes that were mentioned the most as being taken into account by the individuals were the ones positioned closest to the center: freedom, art and craftsmanship, passion, power, innovation, high price and desire. Given the fact that the subject was related to luxury products, respondents highlighted different motivations than the ones attributed to common goods. Even though at the beginning of the interview participants were quiet and unsure, once the discussion went on they became relaxed and interested, even identifying themselves with the research's resulting projections.

The brand's rigid personality has been found to be in close relation with the respondents that did not have a clearly defined clothing style, do not recognize luxury as being indispensable, do not follow trends but tend to be more conservative, give a high importance to the amount of money spent, want quality products for personal rewards and are led by the desire for power and by past consumption experiences. Emotional personality is a characteristic of consumers that are predisposed to surpass obstacles, look for beauty ideals, social elite as individual recognition, the imposition of femininity or masculinity, being strongly influenced by memories and emotions. The cognitive personality of the brand underlines perfection and rationale and addresses luxury clothing connaisseurs. The brand's sophisticated personality brings the expression of exclusivism, is redirected toward consumers that adhere to truly inaccessible luxury. On the other hand, the brand's sincere personality is attributed to individuals that accept luxury clothing as 
being products of craftsmanship and mastery, perceive this type of products as being works of art and the main attribute that they have in mind when choosing luxury clothing is the sense of freedom they feel.

\section{Conclusions}

Consumer motivation represents the key variable in brand management because knowing the behavior of potential clients can determine the success or failure of an existing or newly created brand. Using the results of a content analysis, brand managers can capitalize on the obtained information and make the necessary decisions for improving or developing their brand's image. Consumers are much more receptive to changes that take place within the market and are careful to choose the brand or product closest to their needs and expectations. They are heavily influenced by emotions, past experiences but also the media. Thus the results of the qualitative research can be a real support for brand managers in establishing marketing plans and strategies, because motivation can offer them essential information about the consumer's „black box”.

The limitations of this article are represented by the fact that it offers a succinct first point of view on the importance of consumer motivation for brand managers from luxury companies and does not cover the complete range of variables that they face within the market. Brand managers must keep up with a smart consumer, a consumer that is constantly searching products that are more sophisticated, consumer that is tech-savvy and tech-oriented, with a behaviour that is more difficult to identify. Marketing specialists must take into account the numerous differences between segments of young people and old people when building campaigns. There are many opportunities that must be valued for each generation of users.

A quantitative study meant to provide a more in-depth analysis on the motivations that influence the purchase behaviour of luxury clothing products will be created, study that will be based on the qualitative study that was analysed within this paper. This future research will have respondents that are luxury clothing users, men and women, from the Jones, $\mathrm{X}, \mathrm{Y}$ and $\mathrm{Z}$ generations. The research will have 3 perspectives: the motivation to choose a certain luxury brand, types of motivation that influence the decisional process and the analysis of the relation between socio-demographic criteria and motivation.

\section{References}

Aaker, J. L., 1997, Dimensions of brand personality, JMR, Journal of Marketing Research; Aug 1997; 34, 3; ABI/INFORM Global, p. 347.

Arnould, E., Price, L., Zinkhan, G., 2002, Consumers, McGraw Hill, New York.

Arnold, M. J. \& Reynolds, K. E., 2003, Hedonic shopping motivations, Journal of Retailing, 79, pp. 77-95.

Balmer, J. M. T., \& Greyser, S. A., 2003, Raising the Corporate Marketing Umbrella, Routledge, London.

Baumgartner, H., \& Steenkamp, J. B. E. M., 1996, Exploratory consumer buying behavior: conceptualization and measurement, International Journal of Research in Marketing, 13, pp. 121-137.

Belk, R.W., 2012, Research in Consumer Behavior, Vol. 12, Emerald Book.

Brakus, J., J., Schmitt,B., H., Zarantonello, L., 2009, Brand Experience: What Is It? How Is It Measured? Does It Affect Loyalty?, Journal of Marketing, Vol. 73, No. 3, pp. 52-68, http://www.jstor.org/stable/20619022

Cătoiu, I., Teodorescu, N.,2003, Comportamentul consumatorului, Ed. Uranus, București. 
Cătoiu, I., Teodorescu, N., 2007, Comportamentul consumatorului, Ed. Uranus, București.

Evans, M., Jamal, A., Foxall, G., 2009, Consumer Behaviour, Second Edition, Wiley Publication, West Sussex.

Clark, M. S., \& Mills, J., 1979, Interpersonal attraction in exchange and communal relationships, Journal of Personality and Social Psychology, 37(1), pp. 12-24. http://dx.doi.org/10.1037/0022-

3514.37.1.12.

Fischer, E., \& Arnold, S. J., 1990, More than a labor of love: Gender roles and Christmas shopping, Journal of Consumer Research, 17 (December), pp. 333-345.

Foxal, G. R., \& Bhate, S., 1991, Cognitive style, personal involvement, and situation as determinants of computer use, Technovation, 11(3), pp. 183-199.

García, M., Díaz, A., 2010, Usable and accessible websites in SMEs. Challenges for the future, Revista Latina de Comunicación Social, Vol. 65, pp. 392-409.

Guiot, D., Roux, D., 2010, A second-hand shoppers' motivation scale: antecedents, consequences, and implications for retailers, J. Retail, 86 (4), pp. 355-371.

Hislop, M., 2001, An Overview of Branding and Brand Measurement for Online Marketers. Dynamic Logic's Branding, Vol. 101, pp. 1-22.

Hirschman, E. C., 1983, Predictors of selfprojection, fantasy fulfillment, and escapism, Journal of Social Psychology, 120 (June), pp. 63-76.

Joško Brakus, J., Bernd, H. Schmitt, L., Zarantonello, L., 2009, Brand Experience: What Is It? How Is It Measured? Does It Affect Loyalty?, Journal of Marketing, Vol. 73, No. 3, pp. 52-68.
Hoyer, W. D., \& MacInnis, D. J., 2010, Consumer Behaviour, SouthWestern/Cengage Learning.

Kapferer, J. N., 2008, Strategic Brand Management, Kogan Page, London.

Keller, K., 2001, Building customer-based brand equity: a blueprint for creating strong brands,

Marketing Science Institute, pp. 1-30.

Keller, K. L., 2003, Strategic brand management: building, measuring, and managing brand equity, Prentice Hall.

Kotler, P.T., Keller, K.L., 2012, Marketing Management, 14th Edition, Pearson.

Levy, S., 1959, Symbols for sale, Harvard Buisness Review , 37, pp. 117-124.

McClelland, D., \& Burnham, D., 2000, Power is the great motivator, Harvard Business Review.

Maslow, A.H., 2000, A Theory of Human Motivation, 1943, Originally Published in Psychological Review, 50, pp. 370-396.

Noble, S.M., Griffith, D.A., Adjei, M.T., 2006, Drivers of local merchant loyalty: understanding the influence of gender and shopping motives, J Retail, 82(3):177-88.

Oliver, R., L. (1997), Cognitive, Affective, and Attribute Bases of the Satisfaction Response, Journal of Consumer Research, 20, pp. 41830.

Olson, J. C., 1978, Inferential Belief Formation in the Cue Utilization Process, in NA Advances in Consumer Research Volume 05, Kent Hunt, Ann Abor, MI : Association for Consumer Research, Pages: 706-713.

Overby, J.W., Lee, E.J., 2006, The effects of utilitarian and hedonic online shopping value on consumer preference and intentions, J Bus Res, 59(10-11):1160-6. 
Peter, J. P., Olson, J., 2004, Consumer Behavior and Marketing Strategy, McGraw-Hill.

http://www.iosrjournals.org/iosrjbm/papers/Vol15-issue3/D01531524.pdf (accesat în data de 2.02.2016)

http://www.palgrave.com/resources/sampl e-chapters/9780230392700_sample.pdf

(accesat în data de 2.02.2016)

http://luxurysociety.com/articles/2013/01/ 2013-luxury-industry-predictions-from-theexperts (accesat în data de 10.02.2016)
http://www.reportlinker.com/ci02177/Luxu ry-Goods.html accesat în data de 10.02.2016

http://www.europeanfinancialreview.com/? p=7133 (accesat în data de 10.02.2016)

https://fashionunited.com/global-fashionindustry-statistics (accesat ăn data de 10.02.2016)

https://www.businessoffashion.com/site/up loads/2016/11/The_State_of_Fashion_2017. pdf accesat in data de 7.02.2017 